\title{
Hypoxia leads to necrotic hepatocyte death
}

\author{
Molly K. Smith, ${ }^{1}$ David J. Mooney ${ }^{2}$ \\ ${ }^{1}$ Department of Chemical Engineering, University of Michigan, Ann Arbor, Michigan 48109 \\ ${ }^{2}$ Division of Engineering and Applied Sciences, Harvard University, Cambridge, Massachusetts 02138
}

Received 3 December 2005; revised 27 April 2006; accepted 9 May 2006

Published online 29 September 2006 in Wiley InterScience (www.interscience.wiley.com). DOI: 10.1002/jbm.a.30930

\begin{abstract}
Hepatocyte transplantation is being investigated as a therapy for liver disease; however, its success has been limited by rapid death of the cells following transplantation. This study was dedicated to elucidating the mode of death responsible for loss of transplanted hepatocytes in order to guide future strategies for promoting their survival. Using a tissue engineering model, it was found that the environment within polymer scaffolds containing transplanted cells was hypoxic after 5 days in vivo, with $(90 \pm$ $3) \%$ of hepatocytes existing at $\mathrm{pO}_{2}<10 \mathrm{mmHg}$. The primary mode of hepatocyte death in response to hypoxic conditions of 0 or $2 \mathrm{vol} \%$ oxygen was then determined in vitro. Several assays for features of apoptosis and necrosis demonstrated that hepatocytes cultured in an anoxic environ-
\end{abstract}

ment died via necrosis, while culture at $2 \%$ oxygen inhibited proliferation. These results suggest it will not be possible to prevent hepatocyte death by interfering with the apoptotic process, and hypoxic conditions in the transplants must instead be addressed. The finding that the environment within cell transplantation scaffolds is hypoxic is likely applicable to many cell-based therapies, and a similar analysis of the primary mode of death for other cell types in response to hypoxia may be valuable in guiding future strategies for their transplantation. (C) 2006 Wiley Periodicals, Inc. J Biomed Mater Res 80A: 520-529, 2007

Key words: hepatocyte transplantation; hypoxia; apoptosis; necrosis; liver tissue engineering

\section{INTRODUCTION}

Hepatocyte transplantation is a potentially promising therapy for liver disease; however, this strategy has been critically limited by the death of a majority of the transplanted cells within $\sim 1$ week of their delivery. The trend of rapid death has been reported for most tissue engineering approaches to hepatocyte transplantation, where the cells have been seeded within constructs to contain them or guide their growth. ${ }^{1-3}$ It is hypothesized that the environment inside such constructs is hypoxic due to isolation from the recipient's vasculature, and that this hypoxia is a major factor contributing to the hepatocytes' death. Supporting this idea is work from the field of angiogenesis, which has demonstrated that tissues more than $\sim 100-200 \mu \mathrm{m}$ away from a blood vessel become hypoxic, as this is the diffusion limit for oxygen in most tissues. ${ }^{4}$ Some hepatocyte transplantation studies have also provided results that support this hypothesis. When the cell delivery strat-

Correspondence to: D.J. Mooney, 325 Pierce Hall, 29 Oxford Street, Cambridge, MA 02138, USA; e-mail: mooneyd@deas. harvard.edu

Contract grant sponsor: National Institutes of Health; contract grant number: R01 DE 13349

C 2006 Wiley Periodicals, Inc. egy allows for ingrowth of fibrovascular tissue from the recipient, it has been found that hepatocytes able to survive the initial post-transplant period go on to proliferate and survive long-term. ${ }^{5,6}$ In these studies, successful engraftment of the transplanted cells has been attributed to the presence of blood vessels that grow into the construct and provide oxygen and other nutrients to the hepatocytes.

In addition to understanding the factors that cause the loss of transplanted hepatocyte populations, it is also of interest to elucidate the predominant mode of death that results. It is unclear whether hepatocytes undergo necrosis or apoptosis in response to prolonged severe hypoxic or anoxic conditions. Most previous studies of the mode of death in hepatocytes have been investigations of disease mechanisms (e.g. hepatitis, cirrhosis, and cholestasis) and of insults to the cells that are associated with liver transplant procedures (e.g. ischemia/reperfusion injury, warm vs. cold perfusion, and storage).$^{7-9}$ Often, a mixture of necrosis and apoptosis is reported, with one of the two mechanisms usually accounting for a majority of the cell death. ${ }^{7,10,11}$ However, there has also been some disagreement over which mode of death is most significant in similar injury models. ${ }^{11,12}$ The mechanism of death in response to hypoxia has been investigated for other cell types, and whether the cells die predominantly by necrosis or apoptosis appears to 
partially depend upon the identity of the cells. Some cell types have been shown to upregulate apoptosis suppressors in response to hypoxia, ${ }^{13}$ while others upregulate promoters of apoptosis. ${ }^{14,15}$

Necrosis and apoptosis differ greatly in the ways they affect cells, and knowledge of which is predominant in hepatocytes exposed to hypoxic conditions will dictate the types of strategies that have the most promise for enhancing survival. If a majority of hepatocytes die via apoptosis in response to hypoxia, it may be possible to prevent their death by interfering with the apoptotic pathway. Errors in regulation of apoptosis have been shown to be an important component of many diseases (e.g. cancer, autoimmune diseases, and Alzheimer's) ${ }^{16,17}$ and the regulatory mechanisms have thus been studied extensively to yield knowledge that might be useful in disease prevention or treatment. Two groups of proteins that have been found to be particularly important in determining whether a cell will undergo apoptosis are the Bcl-2 and caspase families. ${ }^{18,19}$ The Bcl-2 family consists of pro-apoptotic (e.g. Bax, Bad) and anti-apoptotic (e.g. Bcl-2, Bcl-xL) proteins, and studies have demonstrated that it is possible to inhibit apoptosis by increasing the quantity of antiapoptotic members within the cell. ${ }^{10,20}$ There are also two groups within the caspase family: initiator caspases, which activate the second group, the effector caspases, which are responsible for cleaving proteins that eventually result in cell death. ${ }^{21,22}$ Inhibiting members of the caspase family has been demonstrated to prevent apoptosis as well. ${ }^{23-25}$ These methods could potentially be useful in enhancing transplanted hepatocyte survival, but only if the dominating mode of death is apoptosis. If, on the other hand, necrosis is the major form of death experienced by hepatocytes in hypoxia, there is not a specifically regulated pathway with which to interfere. Instead, it will be critical to focus on alleviating hypoxia at the transplant site, and otherwise enhancing conditions to promote hepatocyte survival.

In this study, the existence of hypoxic conditions within scaffolds used for hepatocyte transplantation was first investigated to confirm that the cells are indeed exposed to hypoxia upon transplantation. Experiments were then performed in which hepatocytes were cultured in a hypoxic environment and assayed to determine the mode of death that occurs. The results of this investigation promise to help guide strategies for promoting transplanted hepatocyte survival in the future.

\section{MATERIALS AND METHODS}

\section{Scaffold fabrication}

Scaffolds were formed using a modification of a previously published process, ${ }^{26,27}$ which involves fabricating polylactide-co-glycolide (PLG) into microspheres prior to forming scaffolds from the polymer. Microspheres were made using 85:15 PLG (85:15 high i.v. Medisorb, Alkermes; Cambridge, MA) via a standard double emulsion process. ${ }^{28}$ In brief, a $5 \%(\mathrm{w} / \mathrm{v})$ solution of PLG in ethyl acetate (EtAc) (Sigma, St. Louis, MO) was combined with distilled, deionized water in a test tube. This two-phase mixture was then sonicated to yield a single emulsion. An equal volume of an aqueous solution containing 1\% polyvinyl alcohol (PVA; MW 25,000; $88 \%$ hydrolyzed; Polysciences Inc., Warrington, PA) and $7 \%$ EtAc was added to the single emulsion, and the resulting solution was vortexed (Vortex Genie, VWR) to yield the double emulsion. This double emulsion was immediately transferred to a rapidly stirring aqueous solution of $0.3 \%$ PVA $/ 7 \%$ EtAc. After allowing the EtAc to evaporate over a 3-h period, the microsphere-containing solution was filtered to retrieve the microspheres, which were then rinsed with distilled water, flash frozen, and lyophilized.

For each scaffold, $3 \mathrm{mg}$ of microspheres were combined with $150 \mu \mathrm{L}$ of a $0.1 \%$ MVM alginate (Pronova, Oslo, Norway) solution. This mixture was lyophilized to form a powder, combined with $50 \mathrm{mg} \mathrm{NaCl}$ (sieved to yield a particle diameter between 250 and $425 \mu \mathrm{m}$ ), and pressed in a $4.763 \mathrm{~mm}$ diameter die to create a $1.5 \mathrm{~mm}$ thick disk. The PLG was gas foamed by subjecting the disks to 800 psi $\mathrm{CO}_{2}$ for $24 \mathrm{~h}$, followed by a rapid reduction of pressure to ambient. The $\mathrm{NaCl}$ was leached from scaffolds by incubating in $0.1 \mathrm{M} \mathrm{CaCl} \mathrm{Ca}_{2}$ for $16 \mathrm{~h}$ prior to use in experiments. Scaffolds were sterilized by soaking in $100 \%$ ethanol for $20 \mathrm{~min}$, followed by five 5-min washes with sterile PBS.

\section{Hepatocyte isolation}

Hepatocytes were isolated from adult male Lewis rats (150200 g, Charles River Breeding Laboratories, Wilmington, MA) with a modification of the original Seglen two-step collagenase perfusion procedure. ${ }^{29}$ Briefly, the liver was perfused via the portal vein, first with calcium free buffer $(142 \mathrm{mM} \mathrm{NaCl}, 7 \mathrm{mM}$

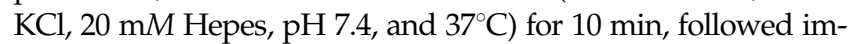
mediately by collagenase containing buffer $(142 \mathrm{mM} \mathrm{NaCl}$, $7 \mathrm{mM} \mathrm{KCl}, 20 \mathrm{mM} \mathrm{CaCl}$, $20 \mathrm{mM}$ Hepes, $0.5 \mathrm{mg} / \mathrm{mL}$ Collagenase Type 2 (Worthington Biochemical), $\mathrm{pH} 7.4$, and $37^{\circ} \mathrm{C}$ ). Perfusion with the collagenase-containing buffer was continued for 7-10 $\mathrm{min}$. The perfused liver was then placed in ice-cold William's Medium E, and cells were dissociated by removing the liver capsule, and gently shaking the hepatocytes free from the remaining liver matrix. This cell suspension was filtered through a $400 \mu \mathrm{m}$ Nytex mesh (Tetko Inc., Elmsford, NY) to remove large debris. The cell yield per liver was $1-2 \times 10^{8}$ and the initial percentage of viable cells was $80-90 \%$. To further purify the cell population and remove cellular debris, density gradient centrifugation using Percoll (Sigma) was performed. The collected hepatocytes, which had a total cell viability greater than $90 \%$, were then placed on ice and immediately used in experiments. NIH guidelines for the care and use of laboratory animals (NIH Publication No. 85-23 Rev. 1985) were observed throughout this study.

\section{SCID mouse implants}

Immediately before matrix implantation, $1 \times 10^{6}$ hepatocytes were suspended in $25 \mu \mathrm{L}$ of a 1:1 mixture of Wil- 
liam's Medium E and growth factor reduced Matrigel ${ }^{\circledR}$ (BD Biosciences, Bedford, MA), and allowed to absorb into the polymer scaffolds for $5 \mathrm{~min}$. The cell seeding efficiency was determined by counting the cells remaining in the dish after this absorption period.

Scaffolds $(n=4)$ were implanted in subcutaneous pockets (2 per animal) on the dorsal region of 7-9 week old male SCID mice (cb17/SCID) (Taconic Labs, Germantown, NY). A $1.5 \mathrm{~cm}$ longitudinal incision was made on the animal's back and the tips of dissecting scissors were slipped under the skin, between the skin and muscle layers, and opened slowly to create spaces into which the implants could be placed. One implant was then placed on either side of the incision, and the incision was closed with two interrupted sutures and covered with tissue adhesive (Mastisol, Ferndale Labs; Ferndale, MI) to help seal the opening. All NIH guidelines for the care and use of laboratory animals (NIH Publication No. 85-23 Rev. 1985) were observed.

\section{Femoral artery ligation}

Ligation of the femoral artery was performed on the left hind limb of mice three days after they received hepatocyteseeded matrices. Animals were anesthetized and a $1 \mathrm{~cm}$ incision was created along the contour between the hindlimb and body of the mouse. Dissecting forceps were then used to tease away the exposed tissue to reveal the femoral artery and vein. Two suture knots were tied around both the artery and vein $\sim 5 \mathrm{~mm}$ apart, and both vessels were severed between the sutures. The incision was then closed with two interrupted sutures and covered with tissue adhesive.

\section{Hypoxyprobe injection and histology}

Hypoxyprobe $^{\mathrm{TM}}$ (Chemicon, Temecula, CA) was used to detect hypoxic tissue regions within the transplanted scaffolds. Muscle tissue surrounding the area of the femoral artery ligation served as a positive control for tissue hypoxia, while muscle tissue from the non-operated hind limb served as a negative control. Five days after scaffold implantation (2 days after femoral artery ligation), mice were intraperitoneally injected with $100 \mu \mathrm{L}$ of a $15 \mathrm{mg} / \mathrm{mL}$ solution of Hypoxyprobe. Animals were killed $1 \mathrm{~h}$ later to retrieve scaffolds and obtain samples of muscle tissue from each hind limb. The dissected tissues were immediately placed into $10 \mathrm{~mL}$ of buffered zinc-formalin, where they remained for $24 \mathrm{~h}$ at $4{ }^{\circ} \mathrm{C}$. The zinc-formalin was then exchanged for $70 \%$ ethanol and samples were stored at $4{ }^{\circ} \mathrm{C}$ until they were embedded in paraffin, sectioned, and mounted on glass slides by the University of Michigan, School of Dentistry Histology Core. Immunostaining for the presence of Hypoxyprobe adducts within the tissue was performed according to the protocol included with the product. To quantify the percentage of hepatocytes existing in hypoxic conditions, positively and negatively stained cells in sections of each scaffold were counted at $200 \times$ magnification.

\section{Hepatocyte culture}

For in vitro studies, hepatocytes were cultured in a defined medium of Williams' Medium E (Invitrogen Life
Technologies, Carlsbad, CA) supplemented with sodium pyruvate (20 mM; Sigma), ascorbic acid (500 ug/mL; Sigma), insulin $(5 \mu \mathrm{g} / \mathrm{mL})$, transferrin $(5 \mu \mathrm{g} / \mathrm{mL})$, selenium (5 ng/mL; ITS supplement, Sigma), dexamethasone (5 nM; Sigma), EGF (10 ng/mL; Peprotech, Inc., Rocky Hill, NJ), and penicillin-streptomycin $(100 \mathrm{U} / \mathrm{mL}$; Invitrogen Life Technologies). The cells were cultured in 6-well tissue culture plates coated with $1 \mu \mathrm{g} / \mathrm{cm}^{2}$ of type 1 bovine collagen (Vitrogen, Cohesion Palo Alto, CA). Collagen coating was performed by diluting the stock collagen solution to a concentration of $4.3 \mu \mathrm{g} / \mathrm{mL}$ in carbonate/bicarbonate buffer (15 mM sodium carbonate, $35 \mathrm{mM}$ sodium bicarbonate, $\mathrm{pH} 9.4$ with glacial acetic acid), aliquoting $3 \mathrm{~mL}$ of this solution per well, and incubating overnight at $4^{\circ} \mathrm{C}$. Wells were rinsed with PBS prior to cell seeding.

Hepatocytes were seeded in prepared plates immediately after isolation, at a density of $2.6 \times 10^{4} \mathrm{cells} / \mathrm{cm}^{2}$ of culture area. Before the cells were subjected to hypoxic culture conditions, they were allowed $36 \mathrm{~h}$ to adapt to culture under typical conditions $\left(37^{\circ} \mathrm{C}, 5 \% \mathrm{CO}_{2}, 20 \% \mathrm{O}_{2}\right)$. To create hypoxic conditions, the culture plates were placed in a modular incubator chamber (Billups-Rothenberg, Inc, Del Mar, CA), which was then flushed with a mixture of either $2 \% \mathrm{O}_{2}, 5 \% \mathrm{CO}_{2}, 93 \% \mathrm{~N}_{2}$, or $0 \% \mathrm{O}_{2}, 5 \% \mathrm{CO}_{2}, 95 \% \mathrm{~N}_{2}$ (vol \%) (Cryogenic Gases, Detroit, MI). Incubator chambers were sealed and placed in a traditional incubator at $37^{\circ} \mathrm{C}$. After $1 \mathrm{~h}$, the chambers were reflushed with the gas mixture to remove ambient gases that may have been trapped in the tissue culture plates. Chambers were also reflushed at 12-h intervals during the culture period, and after medium changes.

\section{Monitoring cell number and survival}

To initially determine the effect of hypoxic conditions on hepatocyte survival and proliferation, changes in cell number were monitored. Hepatocytes were cultured as described earlier in 0,2 , or $20 \%$ oxygen and assayed for cell number just prior to initiating hypoxic culture, and then at 24, 48, and $72 \mathrm{~h}$ afterwards. Changes in total cell number were determined by combining both adherent and floating cells from triplicate samples, and counting them in a model ZM Coulter Counter. For other samples, only adherent hepatocytes were counted to assess the number of cells that were still capable of attaching to the culture surface. To further examine the effect of hypoxia on cell survival, adherent and floating cells were combined and assayed for their ability to exclude trypan blue. Trypan blue solution (Sigma) was added to the cell suspension at a volume ratio of 1:10. After a 2-min incubation, four random fields of cells were counted at $200 \times$ magnification to determine the live and dead fractions.

\section{Annexin $\mathrm{V}$ and propidium iodide labeling}

Hepatocytes exposed to hypoxic conditions were assayed for membrane permeability and externalization of phosphatidyl serine by incubating the cells with propidium iodide and annexin V-EGFP, which binds to extracellular phosphatidyl serine (ApoAlert Apoptosis detection 
kit; BD Biosciences, Palo Alto, CA). The cells were cultured in 0,2 , or $20 \%$ oxygen, and were analyzed 6 and $12 \mathrm{~h}$ after initiating hypoxic conditions. For each sample, $\sim 2 \times 10^{5}$ cells were rinsed with PBS and incubated in the dark for $15 \mathrm{~min}$ with Annexin V-EGFP and propidium iodide (ApoAlert kit). The cells were then visualized under a fluorescence microscope using filter settings for FITC and rhodamine to visualize annexin V-EGFP and propidium iodide, respectively. Three random microscope fields of cells from triplicate samples were photographed on both brightfield and fluorescent settings, and total cell number and positively stained cell number were counted to determine the fraction of cells staining positive for each marker.

\section{Fluorometric assay of caspase-3 activity}

The presence of active caspase-3 in hepatocyte cultures was determined using an established fluorometric assay. ${ }^{30}$ Cells were exposed to 0 or $2 \%$ oxygen for 24,48 , or $72 \mathrm{~h}$ and cells cultured in $20 \%$ oxygen served as a control for background caspase-3 activity. Attached cells were trypsinized and combined with floating cells, for a total of $\sim 3 \times$ $10^{5}$ hepatocytes per sample (triplicate samples were collected for each condition). In brief, the cells were rinsed with PBS, placed at $-80^{\circ} \mathrm{C}$ for $5 \mathrm{~min}$, and then incubated in lysis buffer (50 mM HEPES, $1 \mathrm{mM}$ DTT, $0.1 \mathrm{mM}$ EDTA, $0.1 \%$ CHAPS, and $\mathrm{pH} 7.4$ ) for $45 \mathrm{~min}$ on ice. When lysis was complete, samples were centrifuged and the supernatant cell extract was collected. For each sample, $20 \mu \mathrm{L}$ of cell extract was combined with assay buffer $(100 \mathrm{mM}$ $\mathrm{NaCl}, 50 \mathrm{~m} M$ HEPES, $10 \mathrm{~m} M$ DTT, $1 \mathrm{mM}$ EDTA, 10\% glycerol, $0.1 \%$ CHAPS) in a 96-well plate. Finally, the fluorogenic caspase-3 substrate, Ac-DEVD-AMC (Alexis Biochemicals, San Diego, CA), was added to all wells, and the plate was placed in a fluorometer (GENios; TECAN, Grödig, Austria) with the temperature maintained at $37^{\circ} \mathrm{C}$. DEVDase activity was monitored over the course of $3 \mathrm{~h}$ at excitation and emission wavelengths of 360 and $460 \mathrm{~nm}$, respectively. Purified recombinant human caspase-3 (Alexis) was used as a positive control, and the caspase-3 inhibitor Ac-DEVD-CHO (Alexis) was used to control for nonspecific cleavage of the fluorogenic substrate.

\section{Analysis of DNA degradation}

To isolate and analyze DNA from cultured hepatocytes, a DNA isolation kit was used (Suicide-Track, CalBiochem, San Diego, CA). Again, cells were exposed to 0 or $2 \%$ oxygen for 24,48 , or $72 \mathrm{~h}$, and cells cultured in normoxia $(20 \%)$ served as negative controls. The positive control was supplied with the kit, and consisted of a pellet of HL60 cells that had been treated with actinomycin D for $19 \mathrm{~h}$. Both attached and floating cells were harvested for all conditions, and total DNA was isolated according to the kit instructions from $\sim 8 \times 10^{5}$ cells for each sample. To visualize the pattern of DNA degradation, samples were mixed with loading buffer (supplied with kit) and ethidium bromide and run on a $1.5 \%$ agarose gel in $1 \times$ TAE buffer (50× TAE stock, $242 \mathrm{~g} / \mathrm{L}$ Tris base; $100 \mathrm{~mL} / \mathrm{L}$ 0.5M EDTA; $\mathrm{pH} 8.0 ; 57.1 \mathrm{~mL} / \mathrm{L}$ glacial acetic acid) at 50 constant volts
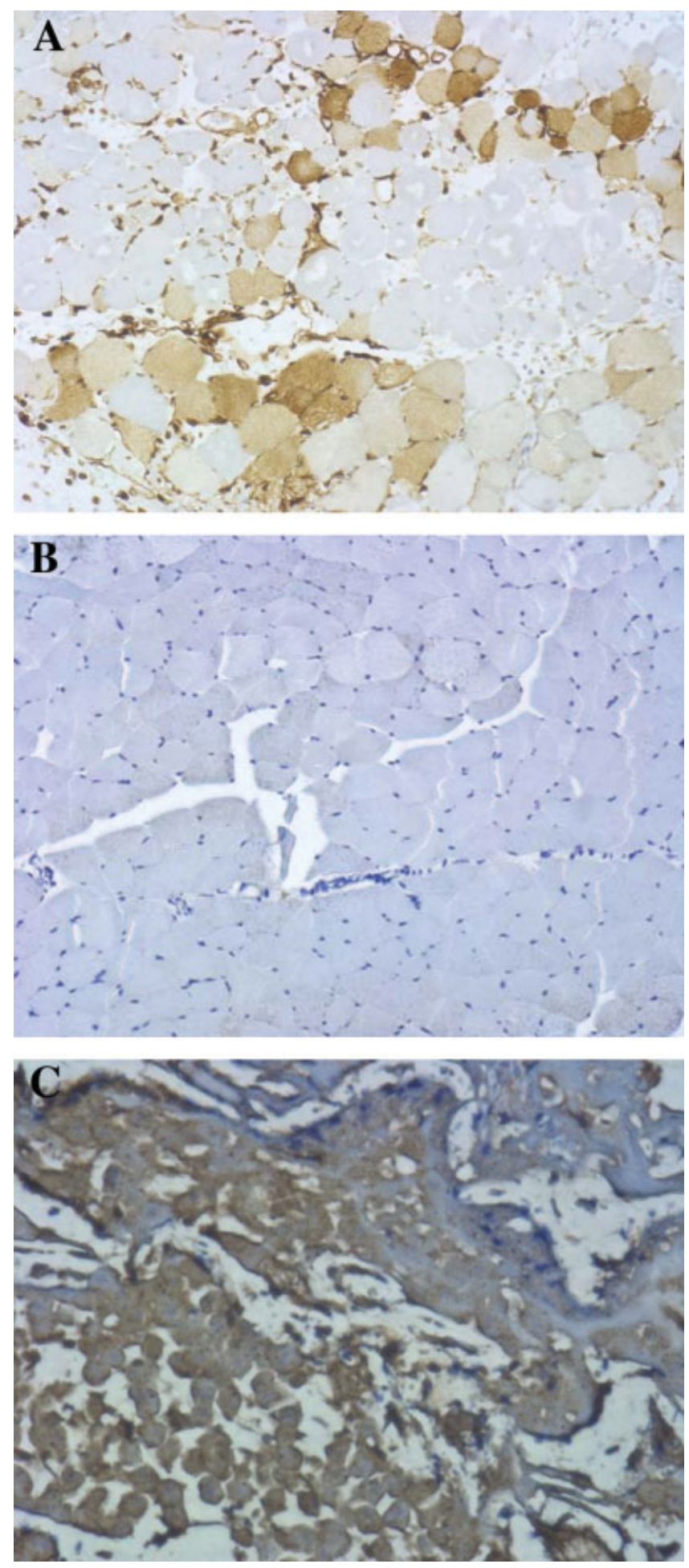

Figure 1. Photomicrographs of hypoxyprobe stained muscle tissue and hepatocyte-containing scaffold. Muscle tissue from hindlimb with ligated femoral artery served as the positive control for hypoxia (A) and tissue from the other hindlimb served as the negative control (B). Transplanted scaffolds containing hepatocytes are largely hypoxic as indicated by positive hypoxyprobe staining throughout a majority of the tissue sections (C). Original magnification was $\times 400$. [Color figure can be viewed in the online issue, which is available at www.interscience.wiley.com.] 
A

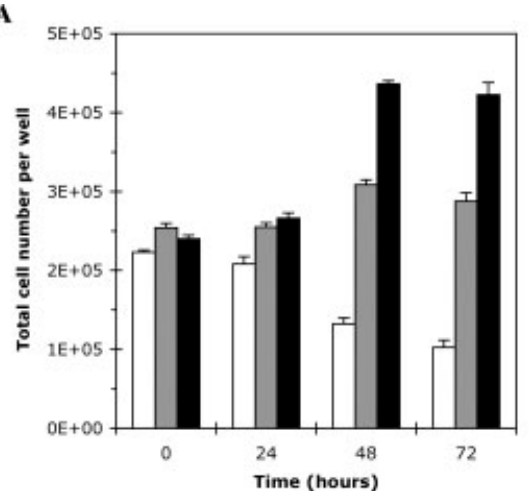

B

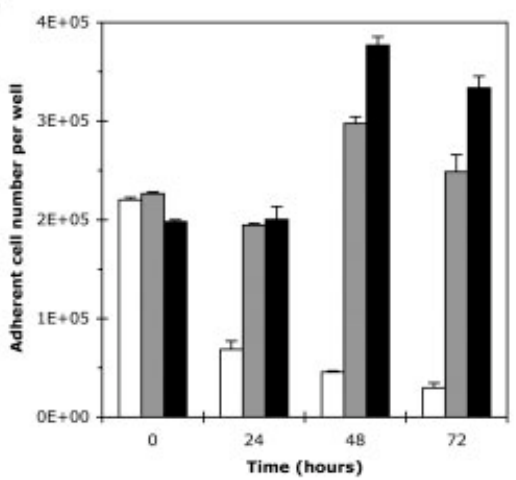

C

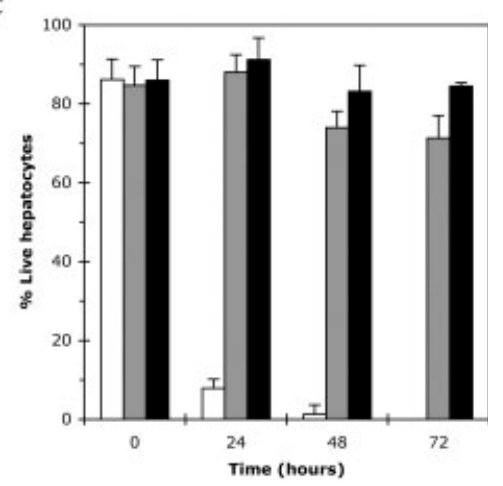

Figure 2. Changes in total hepatocyte number (A), adherent cell number (B), and survival as determined by trypan blue exclusion over time in cultures (C). Culture in $0 \%$ oxygen (white) caused significant declines in cell number and survival $(p<0.05)$. In contrast, culture in $2 \%$ oxygen (grey) led to inhibited proliferation as compared to normoxic control (black) $(p<0.05)$, and had an insignificant effect on survival.

for $\sim 2.5 \mathrm{~h}$. Gels were illuminated with UV light and photographed using a Polaroid GelCam.

\section{RESULTS}

\section{Evaluation of hypoxia at transplant site}

To determine whether the transplant site was a hypoxic environment, a solution of pimonidazole hydrochloride, which forms adducts with thiol groups in proteins only under hypoxic conditions $\left(\mathrm{pO}_{2}<\right.$ $10 \mathrm{mmHg}$ ) was infused into animals receiving hepatocyte transplants. Primary rat hepatocytes were first seeded onto PLG scaffolds, with a seeding efficiency of $(49 \pm 6) \%$, and implanted subcutaneously in SCID mice. Three days after receiving implants, mice had their left femoral artery ligated to provide hypoxic muscle tissue as a positive control. Two days after the ligation was performed, mice were injected with a solution of pimonidazole hydrochloride and sacrificed $1 \mathrm{~h}$ later for retrieval of implants and control tissues. Immunostaining of muscle tissue from the operated and non-operated hind limbs (i.e. the positive and negative control, respectively) confirmed the accuracy of this system in detecting hypoxic tissue regions [Fig. $1(\mathrm{~A}, \mathrm{~B})]$. Observation of immunostained hepatocytecontaining scaffolds revealed that the environment within the scaffolds was significantly hypoxic [Fig. 1(C)]. Quantification of positively and negatively stained hepatocytes indicated that $(90 \pm 3) \%$ of the transplanted cells were positive for hypoxia.

\section{Changes in cell number and survival}

To initially assess the effect of hypoxic conditions on hepatocytes, these cells were cultured with 0,2 , or $20 \%$ oxygen and monitored for changes in the number of total cells (adherent and floating) over the course of $72 \mathrm{~h}$. The total cell number [Fig. 2(A)] re- mained approximately constant for all conditions $24 \mathrm{~h}$ after initiating hypoxic culture, but significant differences became apparent at the $48 \mathrm{~h}$ time point. In the $0 \%$ oxygen condition, hepatocyte numbers had decreased to nearly half the initial value, while the cell numbers in $2 \%$ oxygen increased slightly and the population of cells at normoxia increased by about $65 \%$. The values for 2 and $20 \%$ oxygen remained similar at $72 \mathrm{~h}$, but there was an additional decrease in cell number for the anoxic condition. Analysis of only adherent cells revealed a similar trend for the 2 and $20 \%$ culture conditions, as most of these cells remained attached to the plates [Fig. 2(B)]. The number of adherent cells for $0 \%$ oxygen decreased with time, as did the total number of cells; however, the decline was more rapid and significant when only adherent cells were counted, confirming observations of cell detachment in this condition. Finally, the survival of hepatocytes in all conditions was assessed by the cells' ability to exclude trypan blue [Fig. 2(C)]. The fraction of surviving cells growing in normal conditions remained approximately constant throughout the culture time, decreasing only slightly at the last time point. Culture in $2 \%$ oxygen led to a minor decrease in survival, compared with the normoxia control condition. Anoxic conditions resulted in a significant decline in hepatocyte survival, as only about $10 \%$ of the cells were able to exclude trypan blue after $24 \mathrm{~h}$, and all cells were dead by $72 \mathrm{~h}$.

\section{Annexin V/propidium iodide labeling}

Hepatocytes exposed to hypoxic conditions for 6 or $12 \mathrm{~h}$ were assayed for annexin $\mathrm{V}$ binding, an early indicator of apoptosis, and membrane permeability to propidium iodide, an indicator of necrosis or late apoptosis. Very few cells in any of the conditions were positive for annexin $\mathrm{V}$ binding; cells that did label with annexin $\mathrm{V}$ tended to be floating and were also 

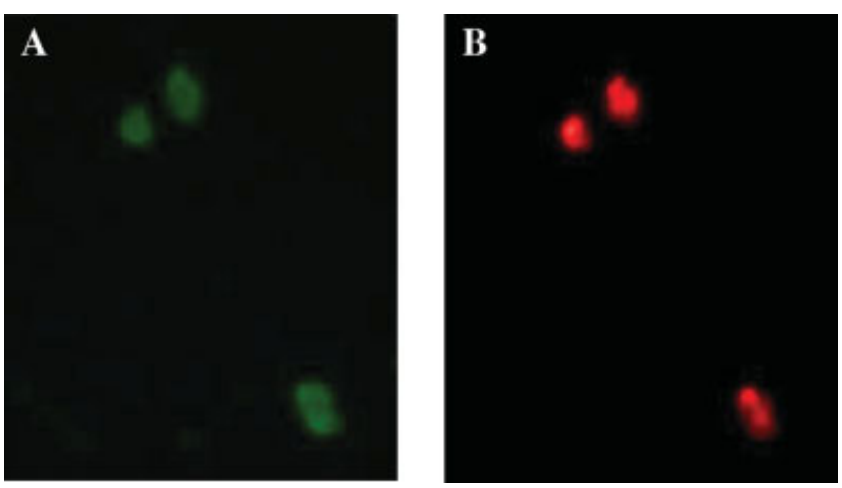

Figure 3. Fluorescent images of hepatocytes that had detached from the culture surface after $6 \mathrm{~h}$ of culture in $2 \%$ oxygen demonstrate positive staining for both annexin $\mathrm{V}$ (A) and propidium iodide (B). These results are indicative of those for floating cells in all conditions. Original magnification $\times 400$. [Color figure can be viewed in the online issue, which is available at www.interscience.wiley.com.]

labeled positively with propidium iodide, suggesting that apoptosis was not occurring (Fig. 3). Analysis was therefore focused on observation and quantification of propidium iodide positive cells. Analysis of the cells via fluorescence microscopy revealed that at both 6 (images not shown) and $12 \mathrm{~h}$ (Fig. 4), a significant portion of hepatocytes exposed to $0 \%$ oxygen were positive for propidium iodide. In contrast, there were only a small number of propidium iodide-positive cells in the 2 and $20 \%$ oxygen conditions. Quantification of the propidium iodide labeling demonstrated an increase in membrane permeability over time for cells cultured under anoxia, with (53 \pm 13$) \%$ and $(70 \pm 8) \%$ of cells positive after 6 and $12 \mathrm{~h}$ in $0 \%$ oxygen, respectively. Less than $1 \%$ of cells cultured in 2 or $20 \%$ oxygen were positive for propidium iodide at both time points.

\section{Assay of caspase 3 activity}

Activation of caspase- 3 was investigated using a fluorometric assay in cells subjected to the experimental conditions for 24,48 , and $72 \mathrm{~h}$. The cell extracts analyzed in the assay were obtained from approximately the same number of hepatocytes for each sample to allow for direct comparison between conditions. Plots of fluorescence intensity versus time were created for each sample, and curves were also integrated to provide an estimate of total fluorescence measured over the course of the assay. Fluorescence intensity increased with time for all samples (except for samples where caspase-3 inhibitor was added) because of accumulation of fluorescent product after cleavage by caspase-3 (Fig. 5). However, none of the samples cultured with low oxygen demonstrated enhanced caspase- 3 activity above that of the negative control samples cultured in normal conditions. Integrat-
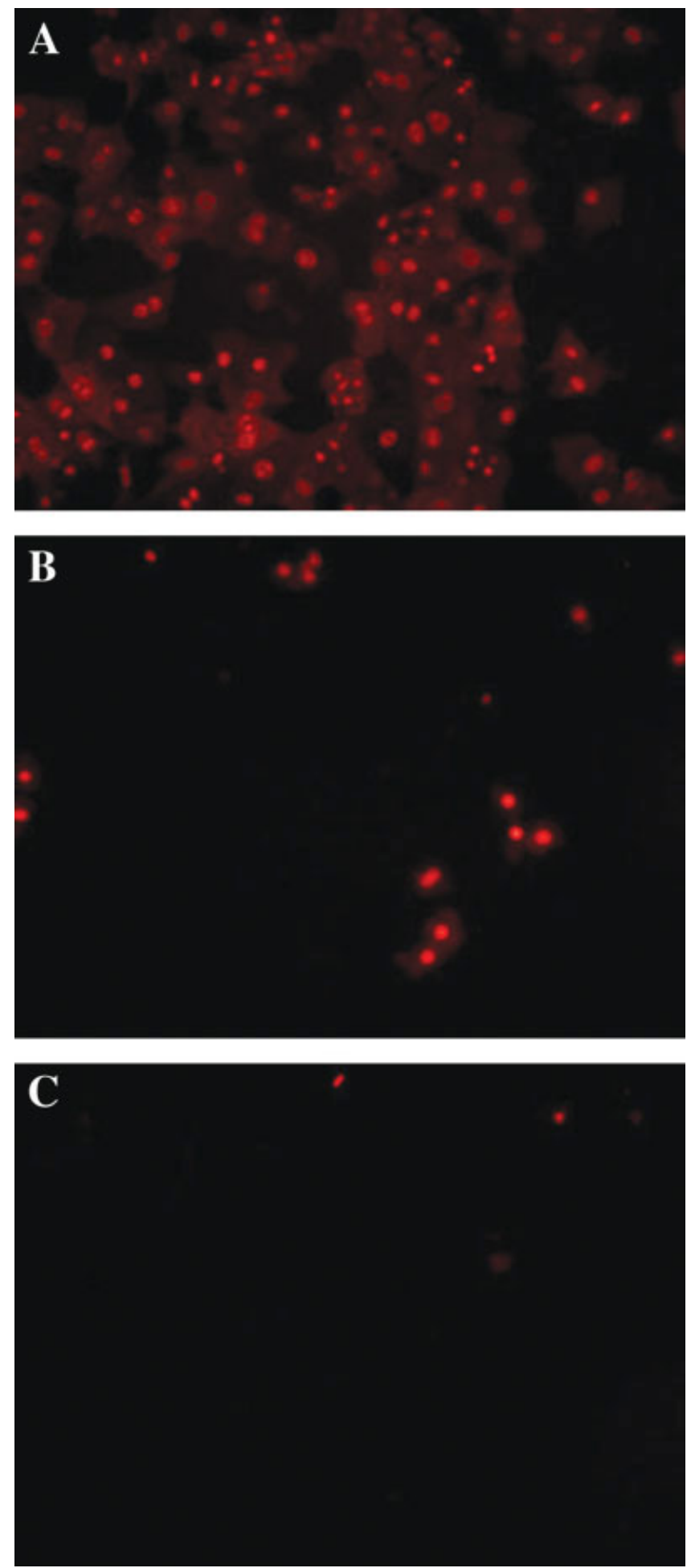

Figure 4. Fluorescent images of adherent hepatocytes incubated with annexin $\mathrm{V}$ and propidium iodide (red fluorescence) after culture in $0 \%(\mathrm{~A}), 2 \%(\mathrm{~B})$ or $20 \%$ (C) oxygen for $12 \mathrm{~h}$. Cells were growing in a confluent monolayer in all conditions. The $0 \%$ oxygen environment led to a marked increase in the fraction of cells that became labeled with propidium iodide. Original magnification $\times 200$. [Color figure can be viewed in the online issue, which is available at www.interscience.wiley.com.] 
A

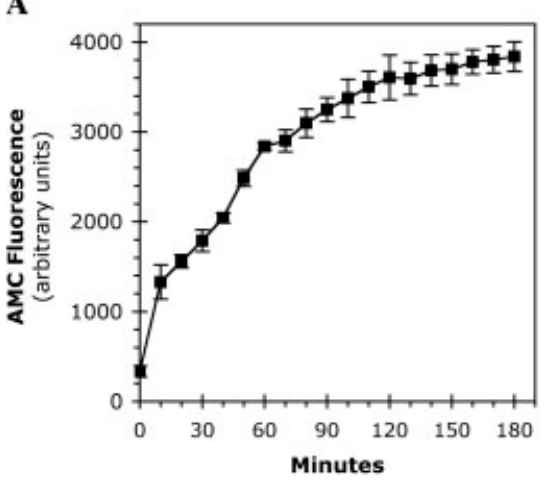

B

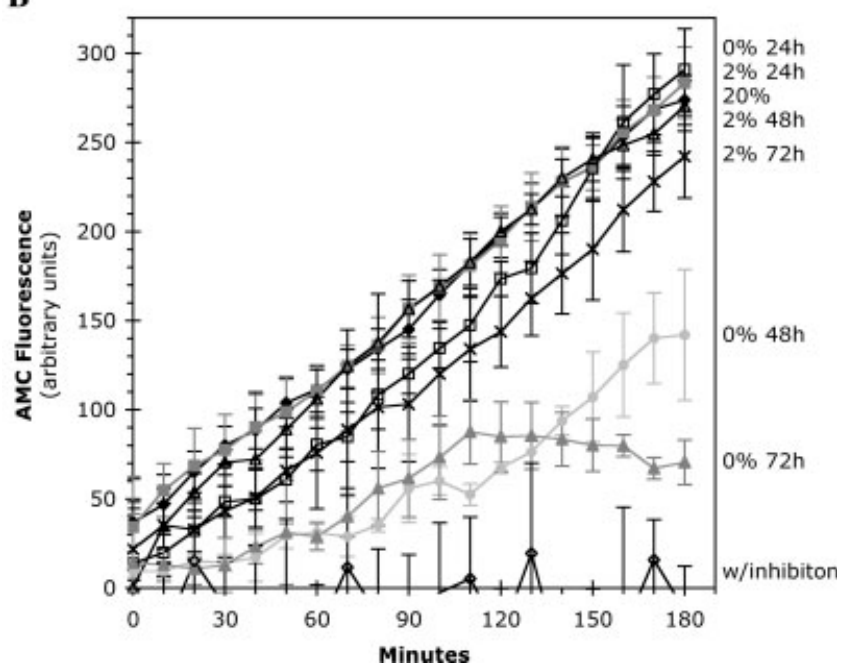

Figure 5. Caspase-3 activity as measured by fluorogenic substrate cleavage over time. (A) The positive control of $1 \mathrm{ng}$ purified caspase- 3 indicates effectiveness of the assay. (B) Samples from experimental hypoxic conditions did not exhibit enhanced caspase- 3 activity above that for the normoxic control.

ing the curves to determine total fluorescence for each sample illustrates this trend more clearly (Fig. 6). It is also evident that there was actually a slight decrease in caspase- 3 activity for hepatocytes cultured in 2\% oxygen for $72 \mathrm{~h}$, and a more dramatic, significant decrease for cells cultured in $0 \%$ oxygen for 48 and $72 \mathrm{~h}$. The general lack of fluorescence measured in samples in which caspase- 3 inhibitor was added confirms the specificity of substrate cleavage by caspase-3. Fluorescence intensity measured for the positive control of purified caspase-3 indicated the functionality of the assay.

\section{Analysis of DNA degradation}

The pattern of DNA degradation in hepatocytes exposed to hypoxic conditions for varying amounts of time was measured to determine whether it was characteristic of necrosis or apoptosis. After $24 \mathrm{~h}$ of exposure to hypoxia there was no apparent degradation of DNA, and the 0 and $2 \%$ oxygen samples

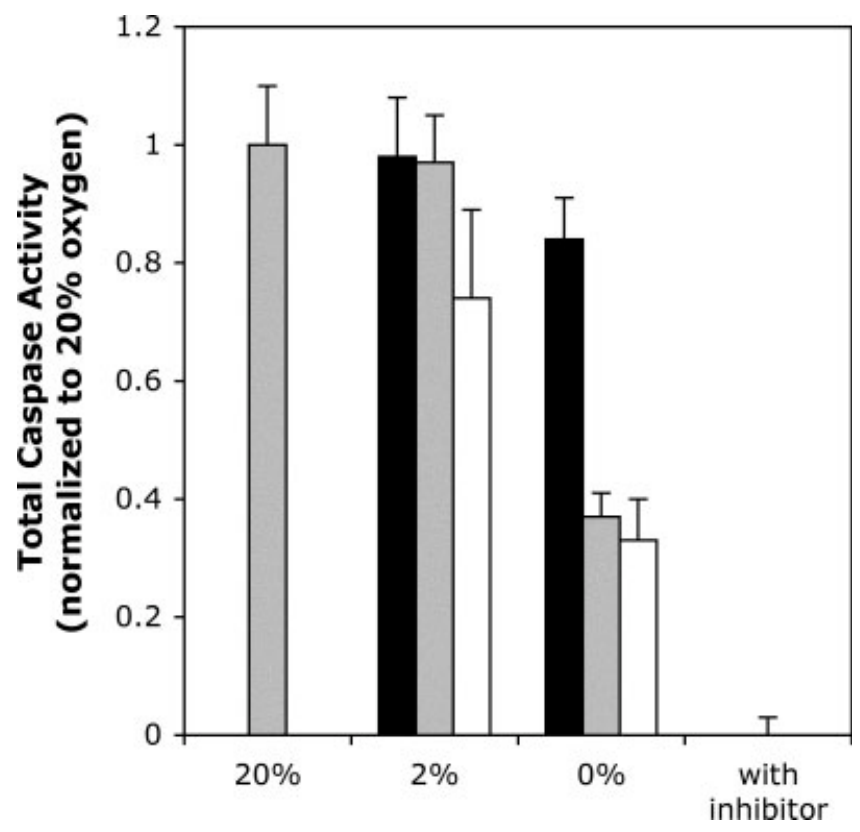

Figure 6. Total caspase-3 activity measured over assay time, as determined by integrating curves of fluorescence versus time, for cells incubated in the various conditions for 24 (black), 48 (grey), or 72 (white) h. Values are normalized to the $20 \%$ oxygen condition at the same time point.

looked identical to the negative controls cultured in normoxia (not shown). When cells were exposed to experimental conditions for 48 and $72 \mathrm{~h}$, however, DNA degradation that was nonspecific in nature became apparent for cells cultured in anoxia (Fig. 7). Even at these longer time points there was no evi-

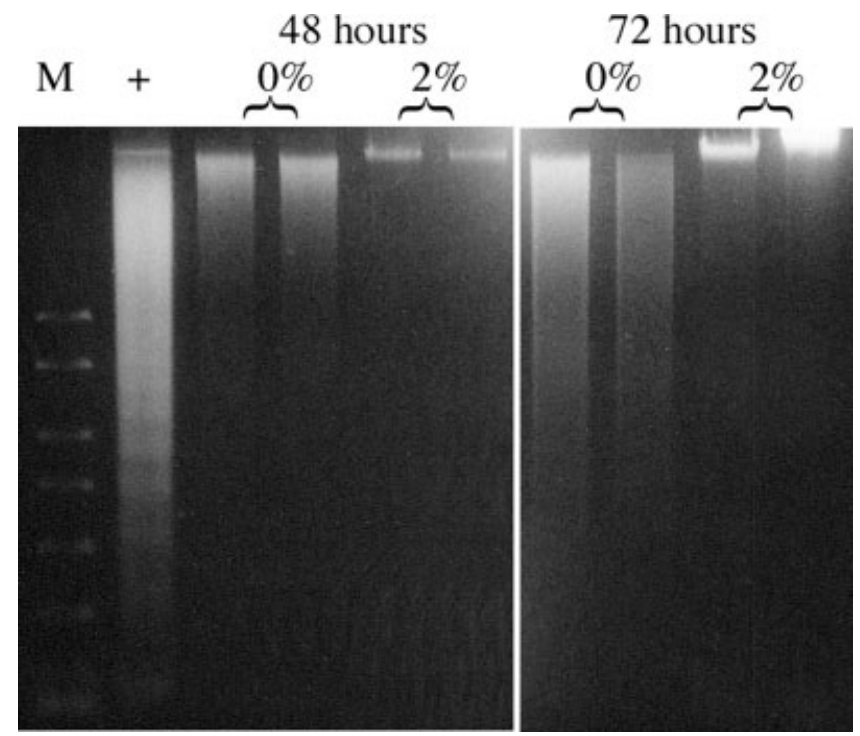

Figure 7. DNA isolated from hepatocytes exposed to hypoxic culture conditions for 48 and $72 \mathrm{~h}$. A positive control $(+)$ for apoptosis demonstrating characteristic DNA ladder and molecular weight marker $(\mathrm{M})$ are also included for reference. 
dence of DNA degradation in samples exposed to $2 \%$ oxygen, and they remained similar in appearance to samples from normal culture conditions.

\section{DISCUSSION}

The results of this in vivo study confirmed that hypoxic conditions exist within three-dimensional constructs used for hepatocyte transplantation, and in vitro studies indicated that hepatocytes' mode of death in response to hypoxia is necrosis. Knowledge of the mechanism of death in transplanted cells may provide insight regarding effective methods to prevent their death in subsequent studies.

Analysis of hepatocytes transplanted subcutaneously to SCID mice within PLG scaffolds revealed that the cells' environment was hypoxic for the 5 days of the study. Immunohistochemical analysis of retrieved implants showed that $\sim 90 \%$ of the transplanted cells were in an environment with a partial pressure of oxygen below $10 \mathrm{mmHg}(\sim 1 \%$ vol \% oxygen). The small fraction of non-hypoxic cells was localized at the outer edges of the implants. This result is not surprising, as it has been generally accepted that the environment of such three-dimensional constructs initially provides insufficient oxygen and other nutrients, due to isolation from the blood supply. ${ }^{31}$ Although expected, this result is significant in that it confirms the existence of hypoxia within the cell delivery constructs.

Several assays indicated that exposure of hepatocytes to $2 \%$ oxygen did not significantly induce cell death, while anoxic culture led to death via necrosis. Measurement of cell numbers over time demonstrated that culture in $0 \%$ oxygen killed a majority of hepatocytes within 2-3 days, and $2 \%$ oxygen slightly inhibited proliferation but did not cause cell death over the same time period. Measurements of cell viability using the trypan blue exclusion assay were consistent with the cell number assay. Permeabilization of the cell membrane is an indicator of necrosis, but it also occurs in the end stages of apoptosis. ${ }^{32}$ Hepatocytes incubated with annexin $\mathrm{V}$ and propidium iodide did not exhibit significant annexin $\mathrm{V}$ binding in any samples after 6 or $12 \mathrm{~h}$ in the experimental culture conditions. However, a majority of cells from the $0 \%$ oxygen condition were positive for propidium iodide after $6 \mathrm{~h}$, and more were positive after $12 \mathrm{~h}$. The lack of annexin $\mathrm{V}$ binding indicates that phosphatidyl serine was not exposed on the outer leaflet of the plasma membrane, which suggests that apoptosis is not occurring, as phosphatidyl serine mislocalization is one of the earliest phenomena of apoptosis. ${ }^{33,34}$ In contrast, the propidium iodide staining of the anoxic cells demonstrates compromised membrane integrity, confirming results from the trypan blue assay, and indicates necrosis as the mode of death. Elevated caspase-3 activity, another early indicator of apoptosis, was not detected in extracts from hepatocytes cultured in 0 or $2 \%$ oxygen for 24,48 , or $72 \mathrm{~h}$, indicating an absence of the apoptotic process. In fact, a significant decrease in caspase- 3 activity was observed in samples from cells that had been maintained in $0 \%$ oxygen for 48 and $72 \mathrm{~h}$. This decline is likely due to proteolysis and cytoplasmic leakage associated with necrotic death. Finally, hepatocytes cultured in $0 \%$ oxygen for 48 or $72 \mathrm{~h}$ exhibited nonspecific DNA degradation consistent with necrosis. During apoptosis, DNA is specifically degraded by endonucleases only between nucleosomes, leaving fragments that are multiples of 180 base pairs. ${ }^{32}$ When electrophoresed on a gel these fragments create a characteristic ladder-like pattern, whereas necrotic DNA creates a nonspecific smear like that evidenced by the hepatocytes cultured in anoxia. Investigations of hepatocytes cultured in anoxic conditions are not prevalent in the literature; however, at least one other group has observed necrosis of anoxic hepatocytes in vitro. ${ }^{35,36}$ Ischemic hepatocytes have also been demonstrated to die primarily via necrosis in a study where fragments of rat liver were left in the peritoneal cavity of other rats for several days. ${ }^{37}$

Interestingly, hepatocytes cultured at $2 \%$ oxygen were resistant to death, although this degree of hypoxia did reduce proliferation of the cells. Hepatocytes in the liver exist along an oxygen gradient within hexagonal subunits of the organ known as lobules, ${ }^{38}$ and there exists a subpopulation of hepatocytes that are adapted to survival in a relatively oxygen-poor environment (corresponding to $\sim 4 \mathrm{vol} \%$ ). Proliferation of the cells in this study was slowed at $2 \%$ oxygen, and metabolic activity was likely affected by this level of hypoxia. ${ }^{39,40}$ It is encouraging that hepatocytes seem able to survive relatively in low oxygen levels, suggesting that even a slight improvement of oxygen transport at the transplant site may have a positive affect.

If other cell types are observed to undergo apoptosis in response to hypoxic conditions in future investigations, it may be possible to prevent their death by interfering with one or more mechanisms of the apoptotic process, as mentioned previously. Specifically, retroviral- or adenoviral-mediated gene transfer techniques could be used to cause the cells to overexpress an apoptotic suppressor, such as Bcl-2 or Bcl-xL. ${ }^{10,20}$ The survival of these genetically altered cells could then be monitored with both in vitro and in vivo studies. Another potential approach, which would be most applicable for in vitro investigation, involves exposing the cells to molecules that inhibit caspase activity to stop the apoptotic pathway, for example, caspases 3 and 9 are inhibited by the molecules Ac-DEVD-CHO and z-LEHD-FMK, respectively. ${ }^{24}$ To 
prevent apoptosis, cells could also be cultured under hypoxic conditions on surfaces coated with fibronectin or laminin, as cellular adhesion to these extracellular matrix molecules has been demonstrated to suppress apoptotic death in a number of reports. ${ }^{41-43}$ Further, lack of enhanced survival when cells are cultured on these ECM molecules could be taken as an indication that apoptosis is not a primary mechanism of cell death, and that apoptosis prevention will not enhance survival. Primary rat hepatocytes have previously been observed to secrete and assemble a significant fibronectin matrix within $30 \mathrm{~h}$ of initiating serum-free culture. ${ }^{44}$ This time-frame correlates well with the $36 \mathrm{~h}$ pre-culture period used in the current study before initiation of anoxia, and the hepatocytes in the present study were thus likely in contact with a fibronectin-enriched extracellular matrix. This suggests that interfering with apoptosis via ECM effects will not prevent hepatocyte death in anoxic conditions.

The results of this work have important implications for enhancing the survival of hepatocytes and other cells transplanted in tissue engineering strategies. It will likely be critical to alleviate the hypoxia as quickly as possible to prevent massive death of the cells. In this investigation it was also found that hepatocytes die via necrosis, not apoptosis, in response to anoxic conditions in vitro, suggesting that future efforts should be focused upon rapid reduction of hypoxia at the transplant site and creation of an environment that promotes hepatocyte survival in ways (e.g. provision of appropriate extracellular matrix, growth factors, hormones) other than interference with apoptosis. Since the mode of death resulting from a given stimulus varies with cell type, efforts to inhibit apoptosis may be effective in addressing the initial loss of other transplanted cell populations.

MKS was supported by a NIH Cellular Biotechnology Training Program fellowship. We thank Alessandra Ennett for assisting with femoral artery ligation surgeries, as well as Jacques Nor and Gaby Mantellini for consulting on apoptosis detection methods.

\section{References}

1. Davis MW, Vacanti JP. Toward development of an implantable tissue engineered liver. Biomaterials 1996;17:365-372.

2. Mooney DJ, Park S, Kaufmann PM, Sano K, McNamara K, Vacanti JP, Langer R. Biodegradable sponges for hepatocyte transplantation. J Biomed Mat Res 1995;29:959-965.

3. Yang MB, Vacanti JP, Ingber DE. Hollow fibers for hepatocyte encapsulation and transplantation: Studies of survival and function in rats. Cell Transplant 1994;3:373-385.

4. Carmeliet P, Jain RK. Angiogenesis in cancer and other diseases. Nature 2000;407:249-257.

5. Mooney DJ, Sano K, Kaufmann PM, Majahod K, Schloo B, Vacanti JP, Langer R. Long-term engraftment of hepatocytes transplanted on biodegradable polymer sponges. J Biomed Mater Res 1997;37:413-420.

6. Kneser U, Kaufmann PM, Fiegel HC, Pollok JM, Kluth D, Herbst H, Rogiers X. Long-term differentiated function of heterotopically transplanted hepatocytes on three-dimensional polymer matrices. J Biomed Mater Res 1999;47:494503.

7. Patel T, Steer CJ, Gores GJ. Apoptosis and the liver: A mechanism of disease, growth regulation and carcinogenesis. Hepatology 1999;30:811-815.

8. Crenesse D, Laurens M, Gugenheim J, Heurteaux C, Cursio $\mathrm{R}$, Rossi B, Schmid-Alliana A. Intermittent ischemia reduces warm hypoxia-reoxygenation-induced JNK/SAPK activation and apoptosis in rat hepatocytes. Hepatology 2001;34:972978.

9. Shimizu S, Eguchi Y, Kamiike W, Akao Y, Kosaka H, Hasegawa J, Matsuda $\mathrm{H}$, Tsujimoto $Y$. Involvement of ICE family proteases in apoptosis induced by reoxygenation of hypoxic hepatocytes. Am J Physiol 1996;271:G949-G958.

10. Shimizu S, Eguchi $Y$, Kamiike W, Itoh $Y$, Hasegawa J, Yamabe K, Otsuki Y, Matusda H, Tsujimoto Y. Induction of apoptosis as well as necrosis by hypoxia and predominant prevention of apoptosis by Bcl-2 and Bcl-XL. Cancer Res 1996; 56:2161-2166.

11. Gujral JS, Bucci TJ, Farhood A, Jaeschke H. Mechanism of cell death during warm hepatic ischemia-reperfusion in rats: Apoptosis or necrosis? Hepatology 2001;33:397-405.

12. Clavien P, Rudiger HA, Selzner M. Mechanism of hepatocyte death after ischemia: Apoptosis versus necrosis [comment]. Hepatology 2001;33:1555-1556.

13. Dong Z, Venkatachalam MA, Wang J, Patel Y, Saikumar P, Semenza GL, Force T, Nishiyama J. Up-regulation of apoptosis inhibitory protein IAP-2 by hypoxia. J Biol Chem 2001; 276:18702-18709.

14. Guo K, Searfoss G, Krolikowski D, Maononi M, Franks C, Clark K, Yu KT, Jaye M, Ivashchenko Y. Hypoxia induces the expression of the pro-apoptotic gene BNIP3. Cell Death Differ 2001;8:367-376

15. Chae HJ, Kim SC, Han KS, Chae SW, An NH, Kim HM, Kim $\mathrm{HH}$, Lee ZH, Kim HR. Hypoxia induces apoptosis by caspase activation accompanying cytochrome $\mathrm{C}$ release from mitochondria in MC3T3E1 osteoblasts. p38 MAPK is related in hypoxia-induced apoptosis. Immunopharmacol Immunotoxicol 2001;23:133-152.

16. Chamond RR, Anon JC, Aguilar CM, Pasadas FG. Apoptosis and disease. Allergy Immunol Clin 1999;14:367-374.

17. Thompson CB. Apoptosis in the pathogenesis and treatment of disease. Science 1995;267:1456-1462.

18. Nunez G, Clarke MF. The Bcl-2 family of proteins: Regulators of cell death and survival. Trends Cell Biol 1994;4:399-403.

19. Kroemer G. The proto-oncogene Bcl-2 and its role in regulating apoptosis. Nat Med 1997;3:614-620.

20. Hockenbery D, Nunez G, Milliman CL, Schreiber RD, Korsmeyer SJ. Bcl-2 is an inner mitochondrial membrane protein that blocks programmed cell death. Nature 1990;348:334336.

21. Studzinski GP. Overview of apoptosis. In: Studzinski GP, editor. Apoptosis: A Practical Approach. New York: Oxford University Press; 1999. pp 1-17.

22. Nunez G, Benedict MA, Hu Y, Inohara N. Caspases: The proteases of the apoptotic pathway. Oncogene 1998;17:3237-3245.

23. Li J, Bombeck CA, Yang S, Kim Y, Billiar TR. Nitric oxide suppresses apoptosis via interrupting caspase activation and mitochondrial dysfunction in cultured hepatocytes. J Biol Chem 1999;274:17325-17333.

24. Ozoren N, Kim K, Burns TF, Dicker DT, Moscioni AD, ElDeiry WS. The caspase 9 inhibitor Z-LEHD-FMK protects human liver cells while permitting death of cancer cells 
exposed to tumor necrosis factor-related apoptosis-inducing ligand. Cancer Res 2000;60:6259-6265.

25. Graf D, Kurz AK, Reinehr R, Fischer R, Kircheis G, Haussinger D. Prevention of bile acid-induced apoptosis by betaine in rat liver. Hepatology 2002;36:829-839.

26. Mooney DJ, Baldwin DF, Suh NP, Vacanti JP, Langer R. Novel approach to fabricate porous sponges of poly(D,L-lactic-co-glycolic acid) without the use of organic solvents. Biomaterials 1996;17:1417-1421.

27. Richardson TP, Mooney DJ. Gas foam processing for tissue engineering applications. In: Atala A, Lanza R, editors. Methods of Tissue Engineering. San Diego, CA: Academic Press; 2001; pp 653-662.

28. Cohen S, Yoshioka T, Lucarelli M, Hwang LH, Langer R. Controlled delivery systems for proteins based on poly(lactic/glycolic acid) microspheres. Pharmacol Res 1991;8:713-719.

29. Aiken J, Cima L, Schloo B, Mooney D, Johnson L, Langer R, Vacanti J. Studies in rat liver perfusion for optimal harvest of hepatocytes. J Pediatr Surg 1990;25:140-144.

30. Mantellini MG, Botero TM, Yaman P, Dennison JB, Hanks $\mathrm{CT}$, Nor JE. Adhesive resin induces apoptosis and cell-cycle arrest of pulp cells. J Dent Res 2003;82:592-596.

31. Colton CK. Implantable biohybrid artificial organs. Cell Transplant 1995;4:415-436.

32. Manjo G, Joris I. Apoptosis, oncosis, and necrosis: An overview of cell death. Am J Pathol 1995;146:3-15.

33. Fadok VA, Voelker DR, Campbell PA, Cohen JJ, Bratton DL, Henson PM. Exposure of phosphatidylserine on the surface of apoptotic lymphocytes triggers specific recognition and removal by macrophages. J Immunol 1992;148:2207-2216.

34. Koopman G, Reutelingsperger CPM, Kuijten GAM, Keehnen RMJ, Pals ST, van Oers MHJ. Annexin V for flow cytometric detection of phosphatidylserine expression of B cells undergoing apoptosis. Blood 1994;84:1415-1420.
35. Bronk SF, Gores GJ. pH dependent non-lysosomal proteolysis contributes to lethal anoxic injury of rat hepatocytes. Am J Physiol 1993;264:G744-G751.

36. Arora AS, Groen PD, Emori Y, Gores GJ. A cascade of degradative hydrolase activity contributes to hepatocyte necrosis during anoxia. Am J Physiol 1996;270:G238-G245.

37. Manjo G, LaGattuta M, Thompson TE. Cellular death and necrosis: Chemical, physical and morphologic changes in rat liver. Virchows Arch Pathol Anat 1960;333:421-465.

38. Sasse D, Spornitz UM, Maly IP. Liver architecture. Enzyme 1992;46:8-32.

39. Jungermann K, Kietzmann T. Oxygen: Modulator of metabolic zonation and disease of the liver. Hepatology 2000;31: 255-260.

40. Hellkamp J, Christ B, Bastian H, Jungermann K. Modulation by oxygen of the glucagon-dependent activation of the phosphoenolpyruvate carboxykinase gene in rat hepatocyte cultures. Eur J Biochem 1991;198:635-639.

41. Zhang Z, Vuori K, Reed JC, Ruoslahti E. The a5b1 integrin supports survival of cells on fibronectin and up-regulates Bcl2 expression. Proc Natl Acad Sci USA 1995;92:6161-6165.

42. Vitale M, DiMatola T, Fenzi G, Illario M, Rossi G. Fibronectin is required to prevent thyroid cell apoptosis through an integrin-mediated adhesion mechanism. J Clin Endocrinol Metab 1998;83:3673-3680.

43. Gu J, Fujibayashi A, Yamada K, Sekiguchi K. Laminin-10/11 and fibronectin differentially prevent apoptosis induced by serum removal via phosphatidylinositol 3-kinase/Akt- and MEK1/ERK-dependent pathways. J Biol Chem 2002;277:1992219928.

44. Stamatoglou SC, Hughes RC, Lindahl U. Rat hepatocytes in serum-free primary culture elaborate an extensive extracellular matrix containing fibrin and fibronectin. J Cell Biol 1987; 105:2417-2425. 